The phenomenon is suppressed when the room is darkened or the patient asked to focus on a near object or to gaze at a plain white surface. But looking at a patterned or printed card did not consistently evoke or enhance the phenomenon as in Evans's experiments. When the patient was asked to scan a patterned or printed card as in reading, the phenomenon was almost invariably evoked or augmented; but it was reduced on scanning a sheet of white paper. The same result was obtained with either eye covered. The results would appear at first sight to confirm Evans's view that the waves are provoked by abrupt changes in the afferent impulses that occur as the focus of macular vision moves over areas of varying brightness. But the relationship with macular stimulation, if any, does not appear to be a specific one even during consciousness. Thus we have repeatedly observed the appearance of the phenomenon following cessation of the mental effort involved in solving a problem. The presence of lambda waves at enhanced amplitude during barbiturate anæsthesia is also evidence against any specific association with visual perception or hallucination ${ }^{2}$ or mental activity. However, these problems, as also the apparent change in the prominence of lambda waves after pre-frontal leucotomy, are matters for further investigation.

\section{Martin Roth} JoY GREEN

Department of Clinical Research, Graylingwell Hospital,

\section{Chichester.}

Aug. 24.

1 Evans, C. C., E.E.G. Clin. Neurophysiol., 5, 69 (1953)

2 Gastaut, Y., Rev. Neurol., 84, 640 (1951).

${ }^{3}$ Fuster, B., Gibbs, E. C., and Gibbs, F. A., Dis. Nerv. Syst., 9, 199 (1948)

${ }^{4}$ Roth, M., E.E.G. Clin. Neurophysiol., 3, 261 (1951).

\section{Effect of Melanophore Hormone on} Regeneration of Visual Purple in Solution

JoRes $^{1}$ considered that melanophore hormone might have a role in night vision, first because nocturnal animals have more melanophore hormone in their hypophysis than diurnal ones; secondly, because the amount of the hormone increases on dark-adaptation; and thirdly because, apart from the hypophysis, the hormone is concentrated only in the eye and thalamus. He presumed that the function of the hormone was to act as a catalyst for the regeneration of visual purple.

By injecting a highly purified fraction of melanophore hormone subcutaneously, I have shown ${ }^{2}$ that this hormone not only shortens the time of dark adaptation but also considerably increases the sensitivity in man. Furthermore, the melanophore hormone was found ${ }^{3}$ to have an augmentative effect on the regeneration of visual purple in situ, using Japanese toads (Bufo vulgaris formosus) into the lymph heart of which the hormone was injected.

Although melanophore hormone accelerates the in vivo regeneration of visual purple, we do not know whether this is due to direct participation in the regenerative process or indirectly by influencing some retinal condition (for example, blood circulation) favourable to regeneration. Some experiments have accordingly been carried out to ascertain how the hormone would act on visual purple itself. At least five frogs (Rana nigromaculata) were decapitated after two hours of dark-adaptation and the eyes enucleated and dissected equatorially under a dim red light in a dark room. The visual purple was extracted with $2-3 \mathrm{ml}$. of sodium-cholate solution. The extract was divided into three equal portions. To two of these portions was added a certain volume of distilled water, while to the third was added a similar volume of melanophore hormone (extracted from the hypophyses of male and female frogs and containing about 50 r.v. per ml.). Each portion of the visual purple solution was then neutralized with $0 \cdot 1-0 \cdot 2 \mathrm{ml}$. of $0 \cdot 1 M$ phosphate buffer. All three solutions were then exposed to 1,500 lux for 10 sec., which reduced the visual purple content to about 75 per cent of that initially present.

Immediately after bleaching, the portion containing melanophore hormone and one of the control portions were incubated in the dark, the other control portion being used for a determination of visual purple content. After incubation for about two hours the amounts of visual purple in the other portions were determined. The amounts of visual purple present were obtained by measuring the change in density occurring on exposure to light. The density measurements were made near the absorption maximum using a filtered light of dominant wave-length $517 \mathrm{m \mu}$ (bandpass width, more than 20 per cent transmitted ; $460-588 \mathrm{~m} \mu)^{3}$. The results obtained are shown in the table.

\begin{tabular}{|c|c|c|c|c|c|c|}
\hline \multirow{3}{*}{$\begin{array}{l}\text { Exp. } \\
\text { No. }\end{array}$} & \multirow{3}{*}{$\begin{array}{c}\text { Vol. of melano- } \\
\text { phore hor- } \\
\text { mone added } \\
\text { to visual } \\
\text { purple solu- } \\
\text { tion }\end{array}$} & \multirow{3}{*}{$\begin{array}{c}\text { Visual } \\
\text { purple } \\
\text { bleached }\end{array}$} & \multicolumn{4}{|c|}{$V$ 'isual purple regenerated } \\
\hline & & & \multicolumn{2}{|c|}{ Control } & \multicolumn{2}{|c|}{ Proof } \\
\hline & & & $\begin{array}{c}\text { Opt. } \\
\text { density }\end{array}$ & $\begin{array}{l}\text { Per } \\
\text { cent }\end{array}$ & $\begin{array}{l}\text { Opt. } \\
\text { den- } \\
\text { sity }\end{array}$ & $\begin{array}{c}\text { Per } \\
\text { cent }\end{array}$ \\
\hline 5 & $0.2-0.65 \mathrm{ml}$ & $0 \cdot 052$ & 0 & 0 & 0.003 & $5 \cdot 8$ \\
\hline 6 & $0 . \overline{1}-0.4$ & 0.041 & 0.007 & $17 \cdot 1$ & 0.011 & $26 \cdot 8$ \\
\hline 7 & $0 \cdot 1-0 \cdot 4$ & 0.047 & 0.007 & $14 \cdot 9$ & 0.032 & $68 \cdot 1$ \\
\hline 8 & $0.2-0.5$ & 0.042 & $-0.006^{*}$ & $-14 \cdot 3$ & 0.013 & $31 \cdot 0$ \\
\hline 9 & $0.2-0.5$ & 0.059 & $-0.003^{*}$ & $-5 \cdot 8$ & 0.016 & $27 \cdot 1$ \\
\hline $10 \dagger$ & $0 . \overline{2}-0.5$ & $0 \cdot 013$ & $-0.002^{*}$ & $-15 \cdot 4$ & 0.020 & $153 \cdot 8$ \\
\hline $11+$ & $0 \cdot 2-0.5$ & 0.052 & $-0.004^{*}$ & $-7 \cdot 7$ & 0.007 & $13 \cdot 5$ \\
\hline $12 \dagger$ & $0.2-0.65$ & $0.02 \overline{2}$ & $-0.002^{*}$ & $-9 \cdot 1$ & 0.004 & $18 \cdot 2$ \\
\hline $13 \dagger$ & $0 \cdot 3-0 \cdot 7$ & $0 \cdot 009$ & $-0.001^{*}$ & $-10 \cdot 1$ & 0.001 & $10 \cdot 1$ \\
\hline $14 \dagger$ & $0 \cdot 1-0 \cdot 25$ & 0.014 & $-0.002^{*}$ & $-14 \cdot 3$ & 0.006 & $42 \cdot 9$ \\
\hline
\end{tabular}

* Negative values indicate degeneration.

+ In these experiments the visual purple was extracted from the outer segments of the rods by Kimura's method (ref. 4).

It is clear from the table that whereas in the controls the amount of visual purple is either only slightly increased, or it may even be degenerated during the incubation period, some regeneration always occurs in those solutions containing melanophore hormone and always to a greater extent than in the controls. 'This indicates that melanophore hormone has an effect on the regenerative process. The very large amount of regeneration observed in experiment No. 10 suggests that there may exist some factor which co-operates with melanophore hormone very effectively. A study of the effect of various factors on the potency of melanophore hormone is now in progress.

TOSHimasa Hanaoka

Laboratory of Physiology,

Institute of Health,

Nara Women's University, Nara, Japan.

Nov. 25, 1952.

${ }^{1}$ Jores, A., Klin. Wochensch., 12, 1599 (1933).

${ }^{2}$ Hanaoka, T., Jap. J. Physiol., 2, 9 (1951).

${ }^{3}$ Hanaoka, T., Annot. Zool. Japon., 24, 137 (1951).

' Kimura, E., Jap. J. Physiol., 3, 25 (1952). 